\title{
Innovative Kimberlite Dike Mining Technologies
}

\author{
Stefan Schwank ${ }^{1}$ and Lars Roesler ${ }^{2}$ \\ IBAUER Maschinen GmbH, Schrobenhausen, Germany, Stefan.Schwank@bauer.de \\ ${ }^{2}$ BAUER Technologies South Africa, Johannesburg, South Africa,Lars.Roesler@bauer.de
}

\section{Introduction}

Mining narrow kimberlite dikes to great depths always has been a challenge for diamond miners. Up to now dikes are mined manually by small scale drill and blast operation, supported by hydraulic jack hammers and small excavators. Mining dikes require high manpower utilization at overall low production rates and significant safety hazards. In inclined dikes mining conditions are even worse.

\section{BAUER Mining Technology}

Development of the cutter technology for diaphragm and cut-off walls for civil engineering applications started at BAUER in 1984 with a newly developed trench cutter for a cut-off wall project in Bavaria, Germany. Based on this first experience, BAUER has continuously developed the trench cutter system over the last 30 years and nowadays has more than 300 units working around the world.
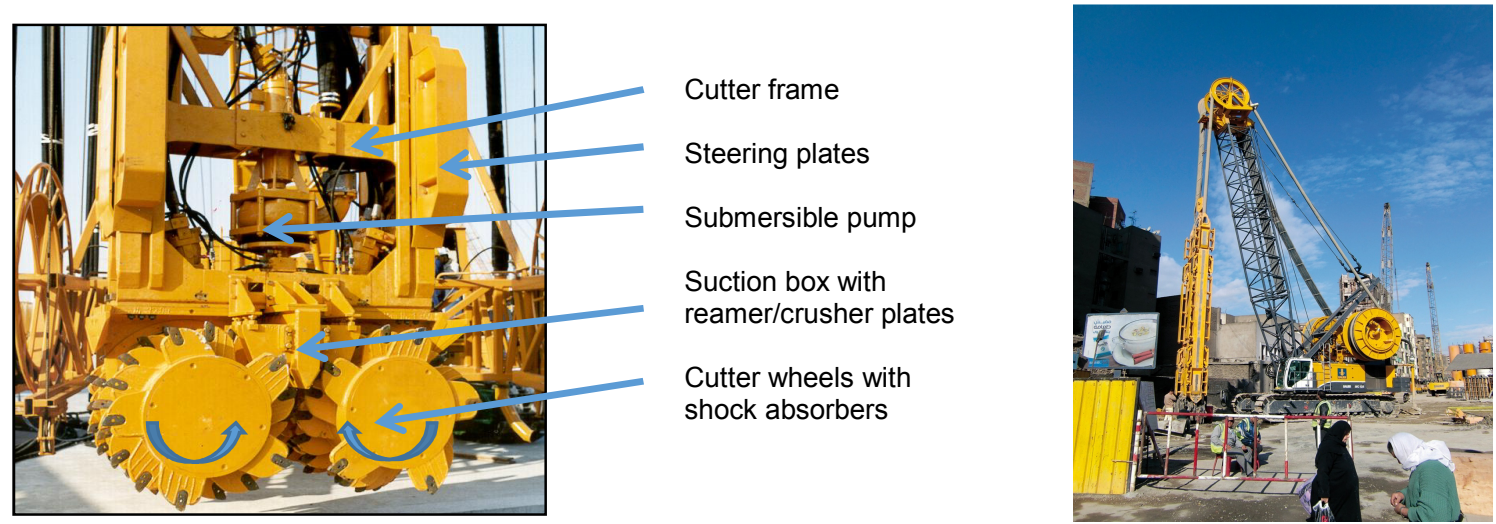

Figure 1: left: Key components of a BAUER trench cutter - right: Cutter arrangement for 150 depth.

Two counter rotating cutter wheels (with a foot print of 3,2 $\mathrm{m} \times 1$ to $4 \mathrm{~m}$ ) equipped with pick teeth attached to a heavy cutter frame, are cutting and crushing the rock to maximum $80 \mathrm{~mm}$ in particle size. Trench Cutter excavations are performed under bentonite slurry (in civil engineering) or water support (in mining) and the cuttings are pumped to surface for recovery in a separation plant.

The cleaned slurry or water is pumped back to the cutter in a closed cycle to minimise consumption. Rocks with a strength of up to $200 \mathrm{MPa}$ have been cut by the BAUER trench cutters. For deep shafts and due to the increased safety requirements in dam construction, cutter systems can now reach a depth of $250 \mathrm{~m}$.

\section{Kimberlite Dike Mining}

The relative small size of the ore body over great length and only little outcrop at surface makes it difficult to mine kimberlite dikes economically. Open-pit mining often comes to an end soon due to the high stripping ratio. Underground mining is expensive for the development time and costs and the tight working condition.

The well proven trench cutter and grab systems of BAUER, are very much suitable to mine these kimberlite dikes mechanically from surface. These hands free diamond mining systems includes primary crushing and with the ore being pumped to the separation plant, leads to a better recovery rate and at the same time avoids several stages of re-handling. 
The width of the dike as well as the strength of the kimberlite determines the size of the excavation tool. For wider trenches or instable host rock conditions, paste back of pillar or of the entire dike, will provide sufficient support for safe working conditions. Very hard ore bodies above approx. $80 \mathrm{MPa}$ uniaxial compressive strength, can be pre-blasted to mine the dikes economically. The success of preblasting however depends on the accuracy of blast and expansion hole drilling, especially in inclined dikes and available expertise in blasting. The BAUER systems are suitable for inclined dikes with not more than 20 degrees from vertical. In such a case, the compressive strength of the ore should be lower than the host rock and the cutter or grab will follow the inclined dike. A special guide frame system is available to start cutter mining with the same inclination as the dike.

Optionally a new cutter head is developed with gripper system to the sidewalls of the trench and high hydraulic forces applied on the cutter head for improved load on bit and thus increased cutter performance in very hard ore.

\section{Kimberlite Dike Mining by Cutter}

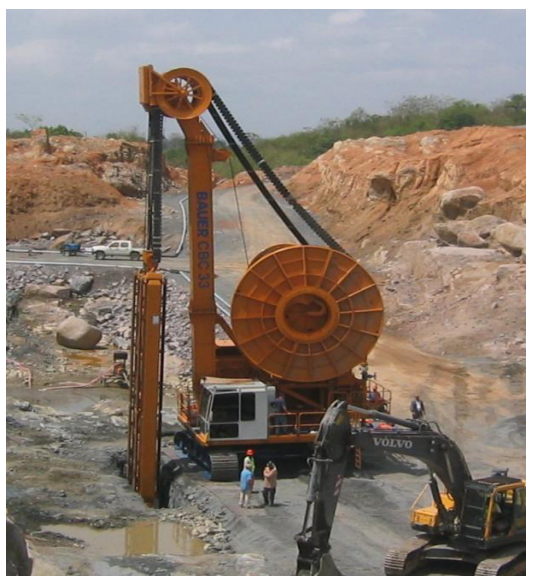

Most of the kimberlite orebodies in eastern Sierra Leone are kimberlite dikes. Jointly the idea was born with our client to use trench cutter equipment as mining tool for these dikes to greater depth. Despite the remote location, it was decided to carry out trial mining with a cutter BC 33 (figure 2). The cutter width chosen was $800 \mathrm{~mm}$, based on the client's assumption of a dike width between 800 and $1000 \mathrm{~mm}$. Trial excavation in kimberlite was undertaken to $40 \mathrm{~m}$ depth.

\section{Kimberlite Large Scale Trial Mining}

BAUER and BHP Billiton together with NUNA Logistics successfully tested the cutter system in a large scale trial mining exercise in the Misery pit of the EKATI mine in the Northwest Territories of Canada.

A trench cutter BC 40, still available in the area from the cut-off wall installation on the DIAVIK diamond mine, was mobilized to the EKATI mine (figure 3). Cutter and separation plant BE 500 were rigged-up at the bottom of the pit, sitting directly on kimberlite ore. Different cutter wheels with different teeth arrangements were tested intensively with parameters being varied such as rotation speed, load on bit and pump speed to find the optimum performance. All ore was pumped to the separation plant and collected in big bags for analysis of size distribution, diamond content, potential diamond breakage and so on. 


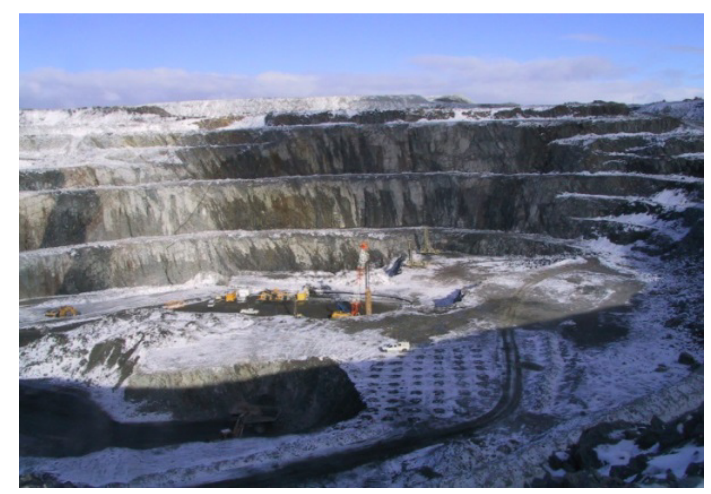

Figure 3: BC 40 in Misery pit, EKATI mine

\section{Diamond Recovery}

Further trials with BAUER cutter were conducted with DeBeers of South Africa to prove the safe recovery of diamonds from on-shore alluvial deposits. BAUER's test pit in Schrobenhausen, Germany, was filled with clay, sand, gravels and cobbles. Red tracers with same specific gravity as diamonds and artificial diamonds were placed within the material at specified locations. Utilizing a standard cutter BC 30 and a standard BE 250 separation plant, the material recovered was screened manually which turned out to be difficult due to the huge amount of material. All except one of the red tracers could be recovered. Overall the tests confirmed that a BAUER cutter can recover even diamonds with a specific gravity of $3.51 \mathrm{~kg} / \mathrm{dm}^{3}$.

\section{Diamond Breakage}

A previous client studied diamond breakage as a result of RC drilling, conventional mining and using the BAUER cutter system. To respect the confidentiality of the client, the Kimberlite deposit and diamond parcel names have been removed, however the results remain intact. The results indicated that the two RC drilling parcels tested had a higher proportion of freshly damaged stones $(40 \%$ and $36 \%$ ) of the diamond population (respectively) than the run of mine parcel $(27 \%)$ and the two BAUER Cutter parcels using the Bauer cutter at $28 \%$. The results suggest that diamond breakage using the BAUER cutter system is consistent with breakage expected in traditional mining methods.

\section{Conclusion - BAUER Cutter Mining - A Selective Sustainable Mining Technology}

The advantages of the BAUER Cutter Mining system are:

- Mechanized, hands free mining of Kimberlite dikes (reduced workforce / higher HSE)

- mining of 'uneconomic' small orebodies

- time to mine is extremely short due to standard equipment used

- selective mining with minimum dilution of ore (reduced environmental impact)

- primary crushing incorporated in the system

- equipment can be used on several orebodies or mine sites.

Mining has always been at the centre of various interests. Economic viability, environmental impact and social acceptance are key factors that have to be balanced to achieve a sustainable mining solution. Dike and vein mining with cutter and grab technology is an excellent example for how to achieve these goals and can not only be applied in kimberlite but also in other commodities like coal and gold veins or uranium dikes.

\section{References}

Schwank S, 2015. Cutter mining - cross-over technology from civil engineering to mining, in Proceedings Third International Future Mining Conference, pp 95-100 (AusIMM; Melbourne). 